EXTENDED REPORT

\title{
Diagnostic and clinical value of anti-cyclic citrullinated peptide antibodies compared with rheumatoid factor isotypes in rheumatoid arthritis
}

\author{
I Vallbracht, J Rieber, M Oppermann, F Förger, U Siebert, K Helmke
}

Ann Rheum Dis 2004;63:1079-1084. doi: 10.1136/ard.2003.019877

See end of article for authors' affiliations

Correspondence to:

Professor Klaus Helmke,

Krankenhaus München-

Bogenhausen, Clinical

Immunology/

Rheumatology,

Englschalkinger Str 77,

81925 Munich, Germany;

Klaus.Helmke@

extern.Irz-muenchen.de

Received

29 December 2003

\begin{abstract}
Objective: To assess the additional diagnostic and clinical value of the second test generation of anti-cyclic citrullinated peptide antibodies (CCP2) compared with rheumatoid factor isotypes (IgG-RF, IgA-RF, IgM$\mathrm{RF}$ ) in patients with rheumatoid arthritis.

Methods: This was a prospective study on 715 patients: rheumatoid arthritis $(n=295)$, degenerative or other inflammatory joint disease $(n=163)$, connective tissue disease or vasculitis $(n=103)$, and healthy controls $(n=154)$. Sera from each subject were tested for CCP2 and RF isotypes by enzyme linked immunosorbent assay (ELISA). Agreement with clinical indices such as disease activity, joint destruction, disease duration, and other laboratory tests was assessed. Sensitivity and specificity of the tests were evaluated taking the clinical diagnosis as the gold standard.

Results: Highest sensitivity was found for IgM-RF (66.4\%) and CCP (64.4\%). Highest specificity was achieved by CCP (97.1\%) and IgG-RF (91.0\%). In rheumatoid patients with high disease activity or severe joint damage, CCP was more often present $(81.4 \%$ and $83.6 \%$ ) than all RF isotypes. Of special diagnostic value was the detection of positive CCP in $34.5 \%$ of all patients with rheumatoid arthritis when all measured RF isotypes (IgG-RF, IgA-RF, and IgM- RF) were negative.

Conclusions: As a screening method for rheumatoid arthritis the IgM-RF and the CCP assays are superior to other RF isotypes. Positivity in the highly specific CCP ELISA supports the diagnosis of rheumatoid arthritis. CCP proved to be a powerful diagnostic tool, especially in ambiguous cases or RF negative patients with rheumatoid arthritis.
\end{abstract}

$\mathrm{R}$ heumatoid arthritis is a systemic, chronic, inflammatory autoimmune disease characterised by joint inflammation that often leads to joint destruction. Rheumatoid arthritis is the most common inflammatory joint disease, affecting $1-2 \%$ of the world population. So far, the diagnosis of this disease has been based primarily on clinical manifestations. However, especially during the first few months of the disease, the 1987 revised criteria of the American College of Rheumatology $(\mathrm{ACR})^{1}$ are rarely met. The highly variable and unpredictable course of the disease suggests the need for highly sensitive and specific diagnostic tests. Serological support is limited and mainly based on the presence of rheumatoid factors (RF). ${ }^{2}$ The specificity and sensitivity of RF have been improved by the development of enzyme linked immunosorbent assays (ELISA), which permits the detection and quantitative measurement of RF in various immunoglobulin classes (IgG-RF, IgA-RF, and IgM-RF), which can be detected in up to $70-80 \%$ of patients with rheumatoid arthritis. ${ }^{3}$ However, RF are not very specific for this disease and can also be detected in other rheumatic disorders, infections, and in apparently healthy individuals. ${ }^{245}$ As the current therapeutic strategies in rheumatoid arthritis recommend increasingly aggressive regimens early in the course of the disease, diagnostic tests with high specificity are desirable for choosing the optimal treatment.

During recent years various circulating non-RF antibodies have been discovered and reported to be of potential diagnostic and clinical value. ${ }^{6-10}$ However, most of these autoantibodies-including antinuclear antibodies (ANA), antiperinuclear factor antibodies (APF), antikeratin antibodies (AKA), and anti-RA33 - could not be shown to have adequate specificity for supporting clinical and therapeutic decisions. Of special interest, however, were the anti-cyclic citrullinated peptide antibodies (CCP), first described by Schellekens ${ }^{11}$ and van Jaarsveld and coworkers. ${ }^{12}$ CCP proved to be very specific in the diagnosis of rheumatoid arthritis, ${ }^{13-16}$ and recent studies have shown that APF and AKA both bind specifically to substrates containing the modified amino acid citrulline. ${ }^{6}{ }^{17}$ The CCP ELISA is based on highly purified synthetic peptides containing modified arginine residues (citrulline) serving as antigen.

We conducted a prospective study to evaluate the additional diagnostic and clinical value of the second generation of CCP antibodies (CCP2) compared with RF isotypes. We evaluated the sensitivity and specificity of all the tests undertaken, and the agreement of all methods with disease activity, radiologically visible joint destruction, and disease duration. We also investigated the presence of CCP in RF negative patients with rheumatoid arthritis.

\section{METHODS \\ Assays \\ RF isotypes}

The RF isotypes for IgG, IgA, and IgM were measured by ELISA. The assay has been described in detail by Jonsson et al. ${ }^{18}$ We used a commercially available test system, Aeskulisa RF-AGM (Aesku.lab Diagnostika, Wendelsheim, Germany). Results were expressed in U/ml. The ELISAs were considered positive at values greater than $15 \mathrm{U} / \mathrm{ml}$. This cut off value was applied to all RF isotypes. For statistical

Abbreviations: ACR, American College of Rheumatology; AKA, antikeratin antibodies; $A P F$, antiperinuclear factor; $A U C$, area under the curve; CCP, anti-cyclic citrullinated peptide; ELISA, enzyme linked immunosorbent assay; RF, rheumatoid factor; ROC, receiver operating characteristic curve; VAS, visual analogue scale 
analysis the results were analysed as continuous and dichotomous variables.

\section{Anti-cyclic citrullinated peptide antibodies}

The CCP ELISA was carried out according to the manufacturer's instructions. We used the commercially available second generation test CCP2 (Immunoscan RA-Mark 2, Euro-Diagnostica BV, Arnhem, Netherlands). Results were expressed in arbitrary units. The samples were considered positive if the antibody titre was greater than 25 arbitrary units. For statistical analysis the results were recorded as continuous and dichotomous variables.

\section{Patients and controls}

We studied 561 patients with suspected rheumatic diseases who attended the hospital between January 1997 and January 2003, and 154 healthy controls. The study population comprised 206 male (28.8\%) and 509 female patients (71.2\%) with a mean (SD) age of 56.8 (18.1) years. The study population included 295 patients with clinically proven rheumatoid arthritis (41.3\%) according to the 1987 revised ACR criteria for the disease. ${ }^{1}$ To analyse the sensitivity and specificity of the tests, we used as controls pooled data from 163 patients with degenerative or other inflammatory joint diseases $(22.8 \%)$, including psoriatic arthritis, reactive arthritis crystal arthropathy, osteoarthritis, and spondylarthropathy, 103 patients with connective tissue disease or vasculitis (14.4\%), and 154 healthy individuals (21.5\%) (table 1).

\section{Clinical evaluation}

The patients were evaluated by clinical examination and laboratory tests. The final clinical diagnosis according to the ACR criteria served as the gold standard for the diagnosis of rheumatoid arthritis. The examiner was blinded to the CCP results at the time of diagnosis. Blood samples were obtained at first clinical presentation and stored at $-20^{\circ} \mathrm{C}$ until assayed. Disease activity of patients with rheumatoid arthritis was assessed at their first visit according to the ACR activity score, including tender joint count (maximum 68), swollen joint count (maximum 66), patient's assessment of pain (VAS), patient's global assessment of disease activity (VAS), physician's global assessment of disease activity (VAS), patient's assessment of physical function (HAQ), ${ }^{19}$ and acute phase reactant value ( $\mathrm{C}$ reactive protein). ${ }^{20}$ An ACR score of $<35$ was defined as low disease activity, between 35 and 65 as moderate, and $>65$ as high.

\section{Radiological evaluation}

In the patients with rheumatoid arthritis, radiographic examination of the hands and feet was done at first presentation. All radiographs were scored by an experienced observer, unaware of the clinical and laboratory data, using the method described by Larsen et al. ${ }^{21}$ A Larsen score of 0-1 was defined as minimal radiological changes. Larsen scores of
2-3 and 4-5 represent moderate and severe radiological changes, respectively.

\section{Statistics}

Correlations between the tests used and disease activity, radiologically visible joint destruction, and disease duration were determined by Spearman's rank correlation. The $\chi^{2}$ test was used to examine the significance of differences in distributions of categorical variables between the different groups. The non-parametric Mann-Whitney U test was used for comparison of continuous variables across different groups. A probability ( $p$ ) value of $<0.05$ was considered statistically significant. The sensitivity and specificity for each assay was determined with respect to the gold standard. In addition, receiver operating characteristic (ROC) analysis was carried out to compare test characteristics independently of predefined cut off points across different tests. All statistical analyses were done with SPSS 11.0.1 statistical software (SPSS Inc, Chicago, Illinois, USA).

\section{RESULTS}

\section{Patient characteristics}

In all, 715 patients were entered into the study. Sera from 202 patients $(28.3 \%)$ were CCP positive, 167 (23.4\%) IgG-RF positive, 199 (27.8\%) IgA-RF positive, and 271 (37.9\%) IgMRF positive by ELISA. The demographic data and the individual test results are shown in table 1. Patients with rheumatoid arthritis had a higher frequency of RF and anticyclic citrullinated antibodies than the control groups. More detailed characteristics of the patients with rheumatoid arthritis, including their clinical characteristics, are shown in table 2 .

\section{Diagnostic value of CCP and RF isotypes}

The highest sensitivity for detecting rheumatoid arthritis was obtained by IgM-RF ELISA (66.4\%) and CCP ELISA (64.4\%). The best specificity was achieved by CCP ELISA (97.1\%) (table 3). Sensitivity for the diagnosis of rheumatoid arthritis could be further increased by a combination of the CCP and RF tests. The combined use of CCP and all RF isotypes (IgG-, IgA-, and IgM-RF) resulted in a respectably high sensitivity of $80.7 \%$ (table 3). Furthermore in our study cohort, seven of the CCP positive patients in the "vasculitis/mixed connective tissue disease" group presented with an articular manifestation (non-erosive arthritis). Perhaps CCP2 has the potential to detect a so far undetected overlap syndrome in these patients.

For further comparisons of the diagnostic value of each assay, we undertook an ROC (receiver operating characteristic) analysis and calculated the area under the curve (AUC). The ROC analysis displays the pairs of sensitivity and specificity for different cut off points of CCP, IgG-RF, IgA$\mathrm{RF}$, and IgM-RF concentrations. The AUC was best for CCP, at 0.84 . The values for IgM-RF, IgA-RF, and IgG-RF were $0.83,0.78$, and 0.74 , respectively (fig 1 ). It could clearly be

Table 1 Patient characteristics

\begin{tabular}{|c|c|c|c|c|c|}
\hline & $\begin{array}{l}\text { RA } \\
\text { (n=295; } 41.3 \%)\end{array}$ & $\begin{array}{l}\text { Degen/inflam joint } \\
\text { disease }(n=163 ; 22.8 \%)\end{array}$ & $\begin{array}{l}\text { Conn tiss disease/vasculitis } \\
\text { ( } n=103 ; 14.4 \% \text { ) }\end{array}$ & $\begin{array}{l}\text { Healthy controls } \\
(n=154 ; 21.5 \%)\end{array}$ & Total $(n=715)$ \\
\hline Female & $237(80.3 \%)$ & $107(65.6 \%)$ & $81(78.6 \%)$ & $84(54.5 \%)$ & $509(71.2 \%)$ \\
\hline Age (mean (SD)) (years) & $62.4(14.7)$ & $56.1(18.4)$ & $51.6(19.1)$ & $50.0(19.7)$ & $56.8(18.1)$ \\
\hline IgG-RF positive & $129(43.7 \%)$ & $11(6.7 \%)$ & $20(19.4 \%)$ & $7(4.5 \%)$ & $167(23.4 \%)$ \\
\hline IgA-RF positive & $150(50.8 \%)$ & $16(9.8 \%)$ & $26(25.2 \%)$ & $7(4.5 \%)$ & $199(27.8 \%)$ \\
\hline IgM-RF positive & $196(66.4 \%)$ & $20(12.3 \%)$ & $44(42.7 \%)$ & $11(7.1 \%)$ & $271(37.9 \%)$ \\
\hline $\mathrm{CCP}$ positive & $190(64.4 \%)$ & $4(2.5 \%)$ & $7(6.8 \%)$ & $1(0.6 \%)$ & $202(28.3 \%)$ \\
\hline
\end{tabular}

$\mathrm{CCP}$, anti-cyclic citrullinated peptide antibodies; Conn tiss, connective tissue; Degen, degenerative; lg, immunoglobulin; inflam, inflammatory; RA, rheumatoid arthritis; RF, rheumatoid factor. 
Table 2 Clinical characteristics of patients with rheumatoid arthritis $(n=295)$

\begin{tabular}{ll}
\hline $\begin{array}{l}\text { Mean disease duration (years) } \\
<1 \text { year* }\end{array}$ & $8.3(10.1)$ \\
$1-5$ years* & $97(32.9 \%)$ \\
$>5$ years* & $59(20.0 \%)$ \\
ACR disease activity score & $139(47.1 \%)$ \\
Patient's assessment of pain (10 cm VAS) & $44.0(27.5)$ \\
Patient's global assessment of disease activity & $4.8(2.6)$ \\
(10 cm VAS) & $4.3(2.1)$ \\
Physician's global assessment of disease activity & \\
(10 cm VAS) & $4.0(2.3)$ \\
Swollen joint count & $6.0(7.1)$ \\
Tender joint count & $12.2(11.3)$ \\
HAQ & $9.7(6.0)$ \\
C reactive protein (mg/l) & $30.4(44.5)$ \\
ACR <35* & $130(44.1 \%)$ \\
ACR 35-65* & $106(35.9 \%)$ \\
ACR $>65^{*}$ & $59(20.0 \%)$ \\
Larsen score & $2.3(1.5)$ \\
Larsen 0-1 & $109(36.9 \%)$ \\
Larsen 2-3 & $115(39.0 \%)$ \\
Larsen 4-5 & $71(24.1 \%)$ \\
\hline Values are mean (SD) or *n (\%). & \\
ACR, American College of Rheumatology; HAQ, health assessment \\
questionnaire; VAS, visual analogue scale. \\
\hline
\end{tabular}

shown that CCP ELISA provided the best combination of sensitivity and specificity for detecting rheumatoid arthritis.

We also analysed the benefit of single or combined use of all four antibody assays. We found an impressive additional diagnostic value of CCP compared with the single use of RF isotypes alone. In $30.8 \%$ of the 295 rheumatoid patients investigated, all four antibodies were positive. However, in 87 patients $(29.5 \%)$ with clinically defined rheumatoid arthritis, the conventionally used RF isotypes (IgG-RF, IgA-RF, and IgM-RF) were all negative. In 30 (34.5\%) of these 87 patients with negative RF isotypes, CCP was still positive. If only the IgM-RF was used as a single RF test (most laboratories only measure RF, and not the RF isotypes), as many as 99 patients with rheumatoid arthritis $(33.6 \%)$ remained undetected. In IgM-RF negative rheumatoid patients, CCP was still positive in $38(38.4 \%)$ of these 99 patients (table 4$)$.

Investigating all 295 rheumatoid patients (not only the 87 RF negative patients), $12.9 \%$ (38/295) were IgM-RF negative but CCP positive. If all three RF isotypes (IgG-RF, IgA-RF, and IgM-RF) were negative, CCP was still positive in $10.2 \%$ (30/295) (table 4). The diagnostic advantage of CCP in RF negative patients was even more convincing in the early course of the disease, where up to $14.4 \%$ (14 of 97) of the rheumatoid patients with a disease duration of less than one year were CCP positive but tested negative for all RF isotypes (IgG-RF, IgA-RF, and IgM-RF), compared with 5.1\% (3/59) and $9.4 \%(13 / 139)$ in rheumatoid patients with a disease duration of $1-5$ or $>5$ years, respectively (table 5 ).

Table 3 Sensitivity and specificity of RF isotypes and CCP: single tests and test combinations

\begin{tabular}{lll}
\hline Assays & Sensitivity (\%) & Specificity (\%) \\
\hline $\lg G-R F$ & 43.7 & 91.0 \\
$\lg A-R F$ & 50.9 & 88.3 \\
$\lg M-R F$ & 66.4 & 82.1 \\
CCP2 & 64.4 & 97.1 \\
$\lg G-/ \lg A-$ or $\lg M-R F$ & 70.5 & 74.5 \\
$\lg$ G-/lgA-/lgM-RF or CCP2 & 80.7 & 73.3 \\
$\lg G-R F$ or CCP2 & 72.9 & 89.0 \\
$\lg A-R F$ or CCP2 & 73.6 & 86.4 \\
$\lg M-R F$ or CCP2 & 79.3 & 80.7
\end{tabular}

CCP2, second generation anti-cyclic citrullinated peptide antibodies; lg, immunoglobulin; RF, rheumatoid factor.

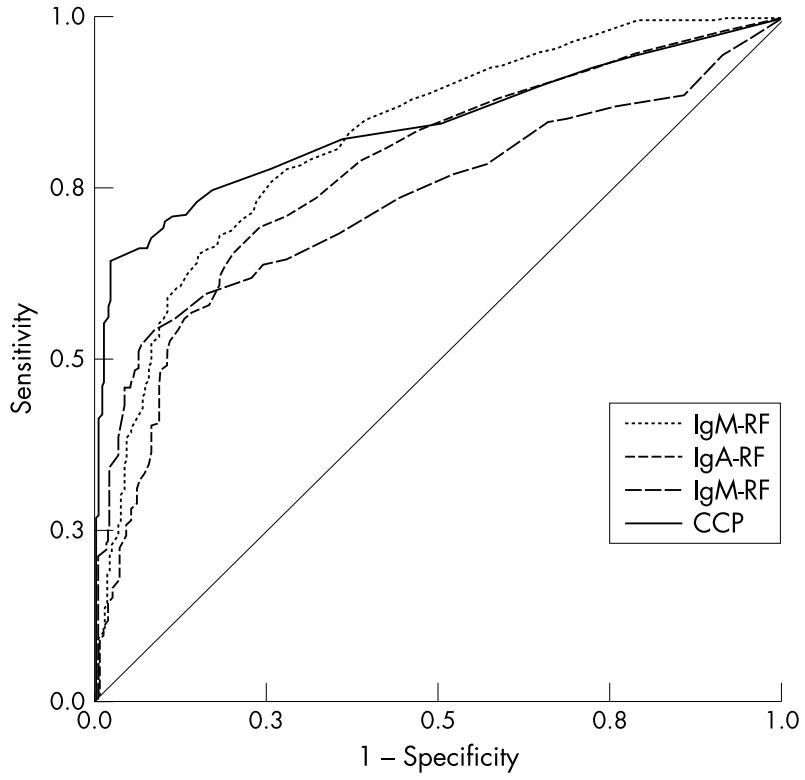

Figure 1 Receiver operating characteristic curves of the anti-cyclic citrullinated peptide antibodies and rheumatoid factor isotypes. CCP, anti-cyclic citrullinated peptide antibodies; Ig, immunoglobulin; RF, rheumatoid factor.

\section{CCP as a marker for disease activity}

A low disease activity was reported in 130 rheumatoid patients $(44.1 \%)$. Moderate or high activity was present in 106 patients $(35.9 \%)$ and 59 patients $(20.0 \%)$, respectively. The percentage of CCP positive rheumatoid patients was significantly higher in those with high disease activity $(81.4 \%), v 58.5 \%$ with low disease activity $(\mathrm{p}<0.05)$ (table 6). In rheumatoid patients with high disease activity, CCP showed a higher sensitivity than all RF isotypes (table 6). The proportion of rheumatoid patients with negative RF isotypes but positive CCP results was much greater in patients with high disease activity than in those with low disease activity, at $17.0 \%(10 / 59) v 8.5 \%$ (11/130) (table 5). Despite this obvious diagnostic advantage of CCP, the best correlation of all the tests performed with disease activity was achieved by IgG-RF $(r=0.281, \mathrm{p}<0.01)$.

\section{CCP as a marker for joint damage}

In our study, 109 rheumatoid patients (36.9\%) presented with minimal, 115 (39.0\%) with moderate, and 71 (24.1\%) with severe joint destruction. Again, in patients with severe joint destruction, CCP was more often positive $(80.3 \%)$ than in patients with minimal joint damage $(54.1 \%) \quad(\mathrm{p}<0.05)$, and showed a higher sensitivity in those with severe joint destruction than all the RF isotypes (table 6). Negative RF isotypes but positive CCP test results were more often found in rheumatoid patients with severe joint destruction than in those with minimal joint destruction: $15.5 \%$ (11/71) v 8.3\% (9/109) (table 5). Of all the tests done, CCP showed the best correlation with joint damage $(r=0.217, \mathrm{p}<0.01)$.

\section{DISCUSSION}

The objective of our study was to assess the additional diagnostic and clinical value of CCP compared with RF isotypes in rheumatoid patients. Rheumatoid arthritis is associated with a few more or less specific autoantibodies ${ }^{32}$; however, most of these have failed to demonstrate adequate diagnostic and prognostic value so far. As there is growing evidence that therapeutic intervention early in the course of rheumatoid arthritis leads to earlier disease control, less joint 
Table 4 Varying combinations of rheumatoid factor and anti-cyclic citrullinated peptide antibodies in 295 patients with rheumatoid arthritis

\begin{tabular}{llll}
\hline RF combinations & All & CCP positive & CCP negative \\
\hline All RA patients & $295(100)$ & $190(64.4)$ & $105(35.6)$ \\
All three RF isotypes positive & $107(36.3)$ & $91(85.0)$ & $16(15.0)$ \\
All three RF isotypes negative & $87(29.5)$ & $30(34.5)$ & $57(65.5)$ \\
At least one RF isotype positive & $208(70.5)$ & $160(76.9)$ & $48(23.1)$ \\
At least one RF isotype negative & $188(63.7)$ & $99(52.7)$ & $89(47.3)$ \\
Only lgG-RF negative & $166(56.3)$ & $86(51.8)$ & $80(48.2)$ \\
Only lgA-RF negative & $145(49.2)$ & $67(46.2)$ & $78(53.8)$ \\
Only IgM-RF negative & $99(33.6)$ & $38(38.4)$ & $61(61.6)$ \\
Only lgG-RF positive & $2(1)$ & $2(100)$ & $0(0.0)$ \\
Only lgA-RF positive & $8(2.7)$ & $4(50)$ & $4(50)$ \\
Only lgM-RF positive & $38(12.9)$ & $26(68.4)$ & $12(31.6)$ \\
At least lgG positive & $129(43.7)$ & $104(80.6)$ & $27(19.4)$ \\
At least lgA positive & $150(50.9)$ & $123(82.0)$ & $44(22.4)$ \\
At least lgM positive & $196(66.4)$ & $152(77.6)$ & \\
\hline Values are $n$ (\%). & & & \\
CCP, anti-cyclic citrullinated peptide antibodies; Ig, immunoglobulin; RA, rheumatoid arthritis; RF, rheumatoid \\
factor.
\end{tabular}

damage, and a better prognosis, ${ }^{23-27}$ it is mandatory to differentiate between rheumatoid arthritis and other forms of arthritis early after symptom development. ${ }^{28}$ Schellekens and coworkers were the first to report on the diagnostic properties of the rheumatoid arthritis specific autoantibodies $\mathrm{CCP}$, using the first generation test CCPI. ${ }^{11}{ }^{13}$

Our study is one of the first to be published using the second generation test, CCP2. The first important finding from our data was that CCP is a highly specific marker in the diagnosis of rheumatoid arthritis. Comparable with the results of other studies using the CCPl assay and of a preproduction test, we found a specificity of $97 \% .^{13} 29$ The somewhat lower specificity and higher sensitivity of other studies using the CCP2 assay may reflect different cut off levels. ${ }^{30}{ }^{31}$ The sensitivity of CCP has also been increased during recent years by the second test generation CCP2 (Immunoscan RA, Mark 2), now comparable in sensitivity to IgM-RF. As in the results of Lee and Schur, ${ }^{30}$ we found a sensitivity of $64 \%$. A higher sensitivity of about $80 \%$ has been described by other investigators. ${ }^{30-34}$ The lower sensitivity in our study cohort may reflect the presence of a relatively high percentage of early rheumatoid patients and a higher cut off level. By combining the use of all four antibodies (CCP or RF isotypes positive), a sensitivity up to $80.7 \%$ can be demonstrated in our study cohort as well.

An additional point of interest in our study cohort was the observation that all the seven CCP positive patients in the "vasculitis/mixed connective tissue disease" group were patients with an articular disease manifestation (non-erosive arthritis). This suggests that these patients may not really have been "false positive" but that the positive CCP results were identifying patients with a so far undetected overlap syndrome.

Our study showed the additional diagnostic and prognostic value of CCP compared with the different RF isotypes. In particular, in RF negative rheumatoid patients, CCP showed convincing additional diagnostic value. CCP could be detected in up to $38.4 \%$ of IgM-RF negative sera of rheumatoid patients. This is of special interest because in many laboratories only IgM-RF and not all RF isotypes are measured routinely. Somewhat lower but comparable results were reported by Sellekens et al, using a preproduction CCP test and IgM-RF assay, ${ }^{13}$ as well as by Lee and Schur, using the CCP2 test and nephelometry as the RF test. ${ }^{30}$ Most of the recent studies that compared CCP and RF have assessed IgM$\mathrm{RF}$ alone as a single marker. ${ }^{13}{ }^{15}{ }^{35}$ In the present study, we compared CCP not only with IgM-RF but also with the other $\mathrm{RF}$ isotypes IgG-RF and IgA-RF in a large population which reflects a broad spectrum of patients with painful joint disease. We found positive CCP results in $34.5 \%$ of patients with rheumatoid arthritis who were negative for IgG-RF, IgA-RF, and IgM-RF. This additional diagnostic value of CCP is even more impressive in the early course of disease, in patients with severe joint destruction, and in patients with very active disease. In the study by Rantapaa-Dalqvist et al, all $\mathrm{RF}$ isotypes (IgG-RF, IgA-RF, and IgM-RF) and CCP2 were also analysed in pre-disease serum samples. ${ }^{36}$ They showed that CCP and IgA-RF predict the development of rheumatoid

Table 5 Additional diagnostic value of anti-cyclic citrullinated peptide antibodies compared with rheumatoid factor isotypes, taking into account disease duration, radiological damage, and disease activity

\begin{tabular}{|c|c|c|c|c|c|}
\hline & All & $\begin{array}{l}\operatorname{lgG} / \lg A / \lg M-R F \\
\text { negative, CCP positive }\end{array}$ & $\begin{array}{l}\text { IgM-RF negative, } \\
\text { CCP positive }\end{array}$ & $\begin{array}{l}\text { IgG-RF negative, } \\
\text { CCP positive }\end{array}$ & $\begin{array}{l}\text { lgA-RF negative, } \\
\text { CCP positive }\end{array}$ \\
\hline All RA patients & $295(100)$ & $30(10.2)$ & $38(12.9)$ & $86(29.2)$ & $67(22.7)$ \\
\hline$<1$ year* & 97 (32.9) & 14 (14.4) & 15 (15.5) & 30 (30.9) & $26(26.8)$ \\
\hline $1-5$ years* & $59(20.0)$ & $3(5.1)$ & $6(10.2)$ & $12(20.3)$ & 7 (11.9) \\
\hline$>5$ years ${ }^{*}$ & $139(47.1)$ & $13(9.4)$ & $17(12.2)$ & 44 (31.7) & $34(24.5)$ \\
\hline Larsen 0-1 & $109(36.9)$ & $9(8.3)$ & $10(8.3)$ & 30 (27.9) & $22(20.2)$ \\
\hline Larsen 2-3 & 115 (39.0) & $10(8.7)$ & 15 (13.0) & 33 (28.7) & $23(20.0)$ \\
\hline Larsen 4-5 & $71(24.1)$ & 11 (15.5) & 13 (18.3) & 23 (32.4) & 22 (31.0) \\
\hline$A C R<35$ & $130(44.1)$ & 11 (8.5) & $14(10.8)$ & 41 (31.5) & 31 (23.9) \\
\hline ACR 35-65 & 106 (35.9) & $9(8.5)$ & $12(11.3)$ & $28(26.4)$ & $24(22.6)$ \\
\hline$A C R>65$ & $59(20)$ & $10(17.0)$ & $12(20.3)$ & 17 (28.9) & $12(20.3)$ \\
\hline
\end{tabular}

Values are $\mathrm{n}(\%)$

*Disease duration.

ACR, American College of Rheumatology disease activity score; CCP, anti-cyclic citrullinated peptide antibodies; Ig, immunoglobulin; Larsen, Larsen radiological score $^{21}$; RA, rheumatoid arthritis; RF, rheumatoid factor. 
Table 6 Sensitivity of CCP/RF isotypes according to disease duration, radiological damage, and disease activity

\begin{tabular}{llllll}
\hline & All & IgG-RF & IgA-RF & IgM-RF & CCP \\
\hline All RA patients & $295(100)$ & $129(43.7)$ & $150(50.8)$ & $196(66.4)$ & $190(64.4)$ \\
$<1$ year* $^{*}$ & $97(32.9)$ & $34(35.0)$ & $35(36.1)$ & $55(56.7)$ & $53(54.7)$ \\
$1-5$ years $^{*}$ & $59(20.0)$ & $31(52.5)$ & $38(64.4)$ & $41(69.5)$ & $40(67.8)$ \\
$>5$ years* & $139(47.1)$ & $64(46.0)$ & $77(55.4)$ & $100(71.9)$ & $97(69.7)$ \\
Larsen 0-1 & $109(36.9)$ & $44(40.4)$ & $50(45.3)$ & $73(67.0)$ & $59(54.1)$ \\
Larsen 2-3 & $115(39.0)$ & $59(44.3)$ & $65(56.5)$ & $75(65.2)$ & $74(64.3)$ \\
Larsen 4-5 & $71(24.1)$ & $34(47.9)$ & $35(48.3)$ & $48(67.6)$ & $57(80.3)$ \\
ACR $<35$ & $130(44.1)$ & $48(36.9)$ & $58(44.6)$ & $85(65.4)$ & $76(58.5)$ \\
ACR 35-65 & $106(35.9)$ & $47(44.3)$ & $50(47.2)$ & $68(64.2)$ & $66(62.3)$ \\
ACR $>65$ & $59(20)$ & $34(57.6)$ & $42(71.2)$ & $43(72.9)$ & $48(81.4)$ \\
\hline
\end{tabular}

Values are $\mathrm{n}(\%)$

*Disease duration.

ACR, American College of Rheumatology disease activity score; CCP, anti-cyclic citrullinated peptide antibodies;

lg, immunoglobulin; Larsen, Larsen radiological score ${ }^{21}$; RA, rheumatoid arthritis; RF, rheumatoid factor.

arthritis, with CCP having the highest predictive value of all four antibodies.

The value of CCP and RF for predicting the outcome of rheumatoid arthritis has been investigated recently. ${ }^{10}{ }^{12}{ }^{14-16}$ Several groups have found that CCP positive patients develop significantly more severe radiographic joint damage, ${ }^{12} 1415$ though all used the less sensitive CCPI test. Our study also showed that determination of CCP and RF isotypes, especially IgG-RF and IgA-RF, contributes to the prediction of clinical disease activity and joint damage. The study by Bas et al, in which the presence of IgM-RF, IgA-RF, and CCP was investigated, also showed an association of IgA-RF and CCP with clinical signs of disease severity. ${ }^{37}$ The high prevalence of CCP in rheumatoid patients with extensive disease activity and severe radiological changes, and even more impressively in rheumatoid patients who are RF negative, suggests that CCP is more useful than the RF isotypes alone in the early prediction of disease outcome and disease activity. Vencovsky et al also showed that in patients with erosive rheumatoid arthritis the combination of CCP positivity and IgM-RF negativity was more common than RF positivity combined with CCP negativity. ${ }^{38}$ Other investigators, such as Paimela et al, have reported that a positive test result of an ELISA based on purified human filaggrin as the antigen failed to predict joint destruction. ${ }^{39}$ Vittecoq et al claimed that RF was the main factor predicting radiological progression, but they used anti-citrullinated rat filaggrin antibodies rather than the currently available CCP2 assay. ${ }^{40}$

\section{Conclusions}

ELISA for IgM-RF is still most useful as a screening marker in the diagnosis of rheumatoid arthritis. However, the second generation CCP ELISA now has a comparable sensitivity, and in addition it has proved to be the most specific marker for the disease. To establish the diagnosis of rheumatoid arthritis, we therefore recommend the use of the highly specific anti-cyclic citrullinated peptide antibody test. Especially in ambiguous cases or in rheumatoid factor negative patients with suspected rheumatoid arthritis, this test has proved very helpful and could be an additional diagnostic marker for the diagnosis of rheumatoid arthritis. Our study suggests that the combined use of RF isotypes and CCP is the most powerful prognostic and diagnostic tool and has greater value for clinical use than conventional RF tests on their own. This set of diagnostic and prognostic markers would allow the clinician to choose a more powerful disease modifying antirheumatic drug early in the course of disease, even when clinical judgment might not yet indicate the need for such drugs.

\section{ACKNOWLEDGEMENTS}

We wish to thank Dr D Roggenbuck, GA Generic Assays GmbH, Dahlewitz, Germany, for donation of a part of the CCP ELISA kits.

\section{Authors' affiliations}

I Vallbracht, M Oppermann, F Förger, K Helmke, Krankenhaus München-Bogenhausen, Clinical Immunology/Rheumatology, Teaching Hospital of the University of Munich, Munich, Germany

J Rieber, Medizinische Klinik München, University of Munich U Siebert, Harvard School for Public Health, Boston, Massachusetts, USA

\section{REFERENCES}

1 Arnett FC, Edworthy SM, Bloch DA, McShane DJ, Fries JF, Cooper NS, et al. The American Rheumatism Association 1987 revised criteria for the classification of rheumatoid arthritis. Arthritis Rheum 1988;31:315-24.

2 Eggeland T, Munthe E. The role of the laboratory in rheumatology. Rheumatoid factors. Clin Rheum Dis 1983;9:135-60.

3 Smolen JS. Autoantibodies in rheumatoid arthritis. In: van Venrooij WJ, Maini RN, eds. Manual of biological markers of disease. Dordrecht: Kluwer, 1996, C1.1/1-18.

4 Thorsteinsson J, Biörnsson OJ, Kolbeinsson A, Allander E, Sigfusson N, Olafsson O. A population study of rheumatoid factor in lceland. A 5 year follow-up of 50 women with rheumatoid factor (RF). Ann Clin Res 1975:7:183-94.

5 Mikkelsen DW, Dodge HJ, Duff IF, Kato H. Estimates on the prevalence of rheumatic diseases in the population of Tecumseh, Michigan, 1959-60. $J$ Chron Dis 1967;20:351-69.

6 Sebbag M, Simon M, Vincent C, Masson-Bessiere C, Girbal E, Durieux JJ, et al. The antiperinuclear factor and the so-called antikeratin antibodies are the same rheumatoid arthritis-specific autoantibodies. J Clin Invest 1995;95:2672-9.

7 Nienhuis RLF, Mandema E, Smids C. A new serum factor in patients with rheumatoid arthritis. The perinuclear factor. Ann Rheum Dis 1964:23:302-5.

8 Mediwake R, Isenberg DA, Schellekens GA, van Venrooij WJ. Use of anticitrullinated peptide and anti-RA33 antibodies in distinguishing erosive arthritis in patients with systemic lupus erythematosus and rheumatoid arthritis. Ann Rheum Dis 2001;60:67-8.

9 Eberhardt KB, Truedsson L, Petterson H, Svensson B, Stigsson L, Eberhardt JL, et al. Disease activity and joint damage progression in early rheumatoid arthritis: relation to $\lg G, \lg A$, and $\lg M$ rheumatoid factor. Ann Rheum Dis 1990;49:906-9.

10 Wiloch HW, Thompson K, Young A, Corbett M, Shipley M, Hay F. IgA and IgM rheumatoid factors as markers of later erosive changes in rheumatoid arthritis (RA). Scand J Rheumatology 1988;75:238-43.

11 Schellekens GA, de Jong BAW, van den Hoogen FHJ, van de Putte LBA, van Venrooii WJ. Citrulline is an essential constituent of antigenic determinants recognized by rheumatoid arthritis-specific autoantibodies. $J$ Clin Invest 1998;101:273-81.

12 van Jaarsveld CHM, ter Borg EJ, Jacobs JWG, Schellekens GA, GmelingMeyling FHJ, van Booma-Frankfort $C$, et al. The prognostic value of the antiperinuclear factor, anti-citrullinated peptide antibodies and rheumatoid factor in early rheumatoid arthritis. Clin Exp Rheumatol 1999;17:689-97.

13 Schellekens GA, Visser $\mathrm{H}$, de Jong BAW, van den Hoogen FHJ, Hazes JMW, Breedveld FC, et al. The diagnostic properties of rheumatoid arthritis antibodies recognizing a cyclic citrullinated peptide. Arthritis Rheum 2000;43:155-63.

14 Meyer O, Labarre C, Dougados M, Goupille P, Cantagrel A, Dubois A, et al. Anticitrullinated protein/peptide antibody assays in early rheumatoid arthritis for predicting five year radiographic damage. Ann Rheum Dis 2003:62:120-6. 
15 Kroot E-JJA, de Jong BAW, van Leeuwen MA, Swinkels $H$, van den Hoogen FHJ, van $t^{\prime}$ Hof $M$, et al. The prognostic value of anti-cyclic citrullinated peptide antibody in patients with recent-onset rheumatoid arthritis. Arthritis Rheum 2000;43:1831-5.

16 Visser H, le Cessie S, Vos K, Breedveld FC, Hazes JMW. How to diagnose rheumatoid arthritis early. A prediction model for persistent (erosive) Arthritis. Arthritis Rheum 2002;46:357-65.

17 Girbal-Neuhauser E, Durieux JJ, Arnaud M, Dalbon P, Sebbag M, Vincent C, et al. The epitopes targeted by the rheumatoid arthritis-associated antifilaggrin autoantibodies are posttranslationally generated on various sites of (pro)filaggrin by deimination of arginine residues. J Immunol 1999;162:585-94.

18 Jonsson T, Arnason JA, Vladimarson H. Enzyme-linked immunosorbent assay (ELISA) screening test for detection of rheumatoid factor. Rheumatol Int 1986;6:199-204.

19 Ekdahl C, Eberhard K, Andersson SI, Svensson B. Assessing disability in patients with rheumatoid arthritis. Use of a Swedish version of the Stanford Health Assessment Questionaire. Scand J Rheumatol 1988;17:263-71.

20 Felson DT, Anderson JJ, Boers M, Bombardier C, Chernoff M, Fried B, et al. The American College of Rheumatology preliminary core set of disease activity measures for rheumatoid arthritis clinical trials. Arthritis Rheum 1993;36:729-40.

21 Larsen A, Dale K, Eek M. Radiographic evaluation of rheumatoid arthritis and related conditions by standard reference films. Acta Radiol 1977;18:481-91.

22 Goldbach-Mansky R, Lee J, McCoy A, Hoxworth J, Yarboro C, Smolen JS, et al. Rheumatoid arthritis associated antibodies in patients with synovitis of recent onset. Arthritis Res 2000;2:236-43.

23 Egsmose C, Lund B, Borg G, Petterson H, Berg E, Brodin U, et al. Patients with rheumatoid arthritis benefit from early 2 nd line therapy: 5 year followup of a prospective double-blind placebo controlled study. J Rheumatol 1995;22:2208-13.

24 Van der Heide A, Jacobs JWG, Bïlsma JWJ, Heurkens AH, van BoomaFrankfort $C$, van der Veen MJ, et al. The effectiveness of early treatment with "second-line" antirheumatic drugs: A randomised, controlled trial. Ann Intern Med 1996; 124:699-707.

25 Symmons DPM, Jones MA, Scott DL, Prior P. Longterm mortality outcome in patients with rheumatoid arthritis: early presenters continue to do well. J Rheumatol 1998;25:1072-7.

26 Anderson JJ, Wells G, Verhoeven AC, Felson DT. Factors predicting response to treatment in rheumatoid arthritis: the importance of disease duration. Arthritis Rheum 2000;43:22-9.

27 Boers M, Verhoeven AC, Markusse HM, van ter Laar MA, Westhovens R, van Denderen JC, et al. Randomised comparison of combined step-down prednisolone, methotrexate and sulphasalazine with sulphasalazine alone in early rheumatoid arthritis. Lancet 1997;350:309-18.

28 Kirwan FC, Quilty B. Prognostic criteria in rheumatoid arthritis: can we predict which patients will require specific anti-rheumatoid treatment? Clin Exp Rheumatol 1997; 15(suppl): 15-25.

29 Jansen ALMA, van der Horst-Bruinsma IE, van Schaardenburg D, van de Stadt RJ, de Koning MHMT, Dijkmans BAC. Rheumatoid factor and antibodies to cyclic citrullinated peptide differentiate rheumatoid arthritis from undifferentiated rheumatoid arthritis in patients with early arthritis. J Rheumatol 2002;29:2074-6.

30 Lee DM, Schur PH. Clinical utility of the anti-CCP assay in patients with rheumatic diseases. Ann Rheum Dis 2003;62:870-4.

31 Suzuki K, Sawada T, Murakami T, Tohma S, Nakazono K, Takemura M, et al. High diagnostic performance of ELISA detection of antibodies to citrullinated antigens in rheumatoid arthritis. Scand J Rheum 2003;32:197-204.

32 Pinheiro GC, Scheinberg MA, Aparecida da Silva M, Maciel S. Anti-cyclic citrullinated peptide antibodies in advanced rheumatoid arthritis. Ann Intern Med 2003; 139:234-5.

33 Van Venrooij WJ, Hazes JM, Visser H. Anticitrullinated protein/peptide antibody and its role in the diagnosis and prognosis of early rheumatoid arthritis. Neth J Med 2002;60:383-8.

34 Vasishta A. Diagnosing early-onset rheumatoid arthritis: the role of anti-CCP antibodies. Am Clin Lab 2002;21:34-6.

35 Zeng X, Ai M, Tian X, Gan X, Shi Y, Song Q, et al. Diagnostic value of anticyclic citrullinated peptide antibody in patients with rheumatoid arthritis. $J$ Rheumatol 2003;30:1451-5.

36 Rantapaa-Dahlquist S, de Jong BA, Berglin E, Hallmans G, Wadell G, Stenlund $\mathrm{H}$, et al. Antibodies against cyclic citrullinated peptide and IgA rheumatoid factor predict the development of rheumatoid arthritis. Arthritis Rheum 2003;48:2741-9.

37 Bas S, Genevay S, Mayer O, Gabay C. Anti-cyclic citrullinated peptide antibodies, $\lg M$ and $\lg A$ rheumatoid factors in the diagnosis of rheumatoid arthritis. Rheumatology 2003;42:677-80.

38 Vencovsky J, Machacek S, Kafkova J, Gatterova J, Pesakova V, Ruzickova S Autoantibodies can be prognostic markers of erosive disease in early rheumatoid arthritis. Ann Rheum Dis 2003:62:427-30.

39 Paimela L, Palosuo T, Aho K, Lukka M, Kurki P, Leirasalo-Repo $M$, et al. Association of autoantibodies to filaggrin with an active disease in early rheumatoid arthritis. Ann Rheum Dis 2001;60:32-5.

40 Vittecoq O, Pouplin S, Krzanowska K, Jouen-Baedes F, Menard JF, Gayet A, et al. rheumatoid factor is the strongest predictor of radiological progression of rheumatoid arthritis in a three-year prospective study in communityrecruited patients. Rheumatology 2003;42:939-46. 